\title{
Buoyancy Effects on Laminar Mixed Convection in Vertical Channel With Dissipation
}

\author{
T. Gopal Reddy ${ }^{1}$, M. Rama Chandra Reddy ${ }^{2}$, B. Rama Bhupal Reddy ${ }^{3}$ \\ ${ }^{1}$ Jr. Lecturer in Mathematics, Government Junior College, Kurnool, A.P., India. \\ ${ }^{2}$ Reader in Mathematics, S.K.S.C. Degree College, Proddatur, A.P., India. \\ ${ }^{3}$ Associate Professor in Mathematics, K.S.R.M. College of Engineering, Kadapa, A.P., India.
}

\begin{abstract}
Deals with the buoyancy effects on laminar mixed convection in vertical channel is considered. Solutions of the governing parabolic equations are obtained by the use of an implicit finite difference technique coupled with a marching procedure. The velocity, the temperature and the pressure profiles are presented graphically for different values of governing parameters like Eckert Number Ek, buoyancy parameter Gr/Re and Prandtl number Pr and their behaviour discussed.
\end{abstract}

Keywords: Mixed convection, Vertical channel, Dissipation

\section{Introduction}

Several authors have presented theoretical or experimental investigations most of which have been reviewed, for instance, in Aung [1]. The literature of the last decades includes many papers presenting theoretical investigations of buoyancy-induced flows in vertical or inclined ducts. Some of these papers (Barletta and Zanchini [7]; Chamkha [9]) describe analytical solutions with reference to fully developed parallel flows. Infact, parallel flow represents the condition that allows a drastic simplification of the governing balance equations, thus giving a chance to find exact solutions at least for the simpler geometries: parallel plane channel, circular or annular duct, rectangular duct. However, if one deals with inclined ducts, the condition of parallel flow can be considered as an exception rather than a rule. This conclusion is a direct consequence of the observation that, in an inclined duct, the buoyancy force vector has a non-vanishing projection on the plane of the duct cross-section. In the fully developed region, the transversal components of the buoyancy force are normally responsible for the onset of a secondary flow that makes velocity a non-parallel helicoidal vector field. It must be pointed out that, in this reasoning, geometry matters. In fact, for a parallel plane channel, parallel flows are still possible when the channel is inclined, for the more commonly employed thermal boundary conditions (Barleta and Zanchini [7]). For different geometries of the duct cross-section, as circular, annular or rectangular, this is not true.

With reference to mixed convection in vertical or inclined plane channels, the fully developed regime has been studied analytically by Aung and Worku [3], Barletta and Zanchini [5, 6]; the flow stability has been investigated numerically by Chen and Chung [10,11]; the reversed flow has been studied experimentally by Gau et al. [13]. Buoyancy effects on Laminar Mixed convection in vertical channels is studied by Reddy [14]. Aung and Worku [2] were discussed the results of a study laminar mixed convection in a parallel plate vertical channel in which the two walls are maintained at uniform but not necessarily equal temperatures. Barletta [4] have been studied laminar mixed convection in a vertical rectangular duct. The analysis refers to thermal boundary conditions such that atleast one of the four duct walls is kept iso-thermal. The evaluation of the velocity field and of the temperature field is performed analytically. Fully developed mixed convection and flow reversal in a vertical rectangular duct with uniform wall heat flux was studied by Barletta [7]. Yih et al. [15] studied numerically heat transfer enhancement in vertical parallel channel with asymmetric walls. Evans and Greif [12] were studied the buoyant in stabilities in downward flow in a symmetrically heated vertical channel.

\section{Nomenclature}

b Distance between the parallel plates

$\mathrm{C}_{\mathrm{p}} \quad$ Specific heat of the fluid

Ek Eckert Number

g Gravitational body force per unit mass (acceleration)

Gr Grashoff number, $\left(\mathrm{g} \beta\left(\mathrm{T}_{1}-\mathrm{T}_{0}\right) \mathrm{b}^{3} / v^{2}\right)$

$\mathrm{k} \quad$ Thermal conductivity of fluid

$\mathrm{p} \quad$ Local pressure at any cross section of the vertical channel

$\mathrm{P} \quad$ Dimensionless pressure inside the channel at any cross section, $\left(\mathrm{p}-\mathrm{p}_{0}\right) / \rho \mathrm{u}_{0}{ }^{2}$ 
Pr Prandtl Number, $\left(\mu \mathrm{C}_{\mathrm{p}} / \mathrm{k}\right)$

$\operatorname{Re} \quad$ Reynolds number, $\left(\left(\mathrm{b} \mathrm{u}_{0}\right) / v\right)$

$\mathrm{T} \quad$ Dimensional temperature at any point in the channel

$\mathrm{T}_{0} \quad$ Ambient of fluid inlet temperature

$\mathrm{T}_{\mathrm{w}} \quad$ Isothermal temperatures of circular heated wall

$\mathrm{T}_{1}, \mathrm{~T}_{2} \quad$ Isothermal temperatures of plate 1 and plate 2 of parallel plates

$\mathrm{u} \quad$ Axial velocity component

$\bar{u} \quad$ Average axial velocity

$\mathrm{u}_{0} \quad$ Uniform entrance axial velocity

$\mathrm{U} \quad$ Dimensionless axial velocity at any point, $\mathrm{u} / \mathrm{u}_{0}$

v Transverse velocity component

$\mathrm{V} \quad$ Dimensionless transverse velocity, $\mathrm{v} / \mathrm{u}_{0}$

$\mathrm{X} \quad$ Axial coordinate (measured from the channel entrance)

$\mathrm{X} \quad$ Dimensionless axial coordinate in Cartesian, (x / (b Re))

y Transverse coordinate of the vertical channel between parallel plates

Y Dimensionless transverse coordinate, $\mathrm{y} / \mathrm{b}$

$\theta \quad$ Dimensionless temperature

$\rho \quad$ Density of the fluid

$\rho_{0} \quad$ Density of the fluid at the channel entrance

$\mu \quad$ Dynamic viscosity of the fluid

$v \quad$ Kinematic viscosity of the fluid, $\mu / \rho$

$\beta \quad$ Volumetric coefficient of thermal expansion

\section{Formulation Of The Problem}

We consider the study flow of an incompressible viscous fluid on developed laminar mixed convection in vertical channels. Figure 1 depict two-dimensional channel between two vertical parallel plates. The distance between the plates is ' $b$ ' i.e., the channel width. The Cartesian coordinate system is chosen such that the $\mathrm{x}$-axis is in the vertical direction that is parallel to the flow direction and the gravitational force ' $\mathrm{g}$ ' always acting downwards independent of flow direction. The y-axis is orthogonal to the channel walls, and the origin of the axes is such that the positions of the channel walls are $y=0$ and $y=b$. One wall is isothermal and other wall is adiabatic condition.

The governing equations for the study viscous flow with the following assumptions are made:

(i) The flow is steady, viscous, incompressible, and developed.

(ii) The flow is assumed to be two-dimensional steady, and the fluid properties are constant except for the variation of density in the buoyancy term of the momentum equation.

After applying the above assumption the boundary layer equations appropriate for this problem are Continuity Equation

$$
\frac{\partial U}{\partial X}+\frac{\partial V}{\partial Y}=0
$$

Momentum Equation

$$
U \frac{\partial U}{\partial X}+V \frac{\partial U}{\partial Y}=-\frac{d P}{d X}+\frac{G r}{\operatorname{Re}} \theta+\frac{\partial^{2} U}{\partial Y^{2}}
$$

Energy Equation

$$
U \frac{\partial \theta}{\partial X}+V \frac{\partial \theta}{\partial Y}=\frac{1}{\operatorname{Pr}} \frac{\partial^{2} \theta}{\partial Y^{2}}+E k\left(\frac{\partial U}{\partial Y}\right)^{2}
$$

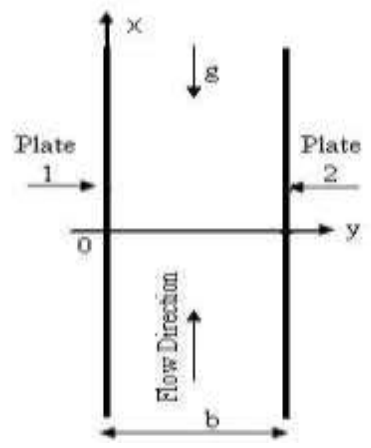

Figure 1: Schematic view of the system and coordinate axes corresponding to Up-flow 
The form of continuity equation can be written in integral form as

$\int_{0}^{1} U d Y=1$

The boundary conditions are

Entrance conditions

At $\mathrm{X}=0,0<\mathrm{Y}<1: \mathrm{U}=1, \mathrm{~V}=0, \theta=0, \mathrm{P}=0$

No slip conditions

At $\mathrm{X}>0, \mathrm{Y}=0 \quad: \mathrm{U}=0, \mathrm{~V}=0$

At $\mathrm{X}>0, \mathrm{Y}=1 \quad$ : $\mathrm{U}=0, \mathrm{~V}=0$

Thermal boundary conditions

At $\mathrm{X}>0, \mathrm{Y}=0 \quad: \quad \theta=1$

At $\mathrm{X}>0, \mathrm{Y}=1 \quad:\left(\frac{\partial \theta}{\partial Y}\right)_{Y=1}=0$

In the above dimensionless parameters have been-efined as:

$\mathrm{U}=\mathrm{u} / \mathrm{u}_{0}, \mathrm{~V}=\mathrm{vb} / \mathrm{v}, \mathrm{X}=\mathrm{x} /(\mathrm{b} \mathrm{Re}), \mathrm{Y}=\mathrm{y} / \mathrm{b}$

$\mathrm{P}=\left(\mathrm{p}-\mathrm{p}_{0}\right) / \rho \mathrm{u}_{0}^{2}, \operatorname{Pr}=\mu \mathrm{C}_{\mathrm{p}} / \mathrm{k}, \operatorname{Re}=\left(\mathrm{b} \mathrm{u}_{0}\right) / v$

$\mathrm{Gr}=\mathrm{g} \beta\left(\mathrm{T}_{1}-\mathrm{T}_{0}\right) \mathrm{b}^{3} / v^{2}, \theta=\left(\mathrm{T}-\mathrm{T}_{0}\right) /\left(\mathrm{T}_{1}-\mathrm{T}_{0}\right)$

The systems of non-linear equations (1) to (3) are solved by a numerical method based on finite difference approximations. An implicit difference technique is employed whereby the differential equations are transformed into a set of simultaneous linear algebraic equations.

\section{Numerical Solution}

The solution of the governing equations for developing flow is discussed in this section. Considering the finite difference grid net work of figure 2, equations (2) and (3) are replaced by the following difference equations which were also used in [8].

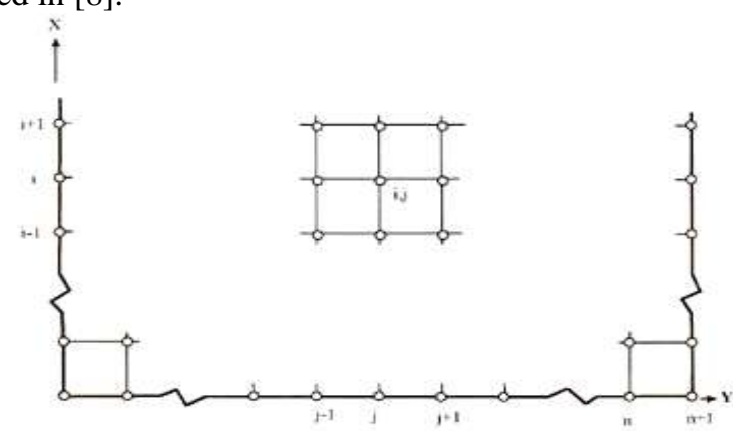

Figure 2: Mesh Network for Difference Representations

$$
\begin{aligned}
& U(i, j) \frac{U(i+1, j)-U(i, j)}{\Delta X}+V(i, j) \frac{U(i+1, j+1)-U(i+1, j-1)}{2 \Delta Y} \\
& =\frac{U(i+1, j+1)-2 U(i+1, j)+U(i+1, j-1)}{(\Delta Y)^{2}}-\frac{P(i+1)-P(i)}{\Delta X}+\frac{G r}{\operatorname{Re}} \theta(i+1, j) \\
& U(i, j) \frac{\theta(i+1, j)-\theta(i, j)}{\Delta X}+V(i, j) \frac{\theta(i+1, j+1)-\theta(i+1, j-1)}{2 \Delta Y} \\
& =\frac{1}{\operatorname{Pr}} \frac{\theta(i+1, j+1)-2 \theta(i+1, j)+\theta(i+1, j-1)}{(\Delta Y)^{2}}+E k\left(\frac{U(i+1, j+1)-U(i+1, j-1)}{2 \Delta Y}\right)^{2}
\end{aligned}
$$

\section{Numerical representation of the Integral Continuity Equation}

The integral continuity equation can be represented by the employing a trapezoidal rule of numerical integration and is as follows: 
$\left[\sum_{j=1}^{n} U(i+1, j)+0.5(U(i+1,0)+U(i+1, n+1))\right] \Delta Y=1$

However, from the no slip boundary conditions

$\mathrm{U}(\mathrm{i}+1,0)=\mathrm{U}(\mathrm{i}+1, \mathrm{n}+1)=0$

Therefore, the integral equation reduces to:

$\left[\sum_{j=1}^{n} U(i+1, j)\right] \Delta Y=1$

A set of finite-difference equations written about each mesh point in a column for the equation (7) as shown:

$$
\begin{aligned}
& \beta_{1} U(i+1,1)+\gamma_{1} U(i+1,2)+\xi P(i+1)+\frac{G r}{\operatorname{Re}} \theta(i+1,1)=\phi_{1} \\
& \alpha_{2} U(i+1,1)+\beta_{2} U(i+1,2)+\gamma_{2} U(i+1,3)+\xi P(i+1)+\frac{G r}{\operatorname{Re}} \theta(i+1,2)=\phi_{2} \\
& -\ldots \ldots \ldots \\
& \alpha_{n} U(i+1, n-1)+\beta_{n} U(i+1, n)+\xi P(i+1)+\frac{G r}{\operatorname{Re}} \theta(i+1, n)=\phi_{n}
\end{aligned}
$$

where

$$
\begin{aligned}
& \alpha_{k}=\frac{1}{(\Delta Y)^{2}}+\frac{V(i, j)}{2 \Delta Y}, \quad \beta_{k}=-\left[\frac{2}{(\Delta Y)^{2}}+\frac{U(i, j)}{\Delta X}\right] \\
& \gamma_{k}=\frac{1}{(\Delta Y)^{2}}-\frac{V(i, j)}{2 \Delta Y}, \quad \xi=\frac{-1}{\Delta X}, \quad \phi_{k}=-\left[\frac{P(i)+U^{2}(i, j)}{\Delta X}\right]
\end{aligned}
$$

for $\mathrm{k}=1,2 \ldots \mathrm{n}$

A set of finite-difference equations written about each mesh point in a column for the equation (8) as shown:

$$
\begin{aligned}
& \bar{\beta}_{1} \theta(i+1,1)+\bar{\gamma}_{1} \theta(i+1,2)+------------=\bar{\phi}_{1}-\bar{\alpha}_{1} \\
& \bar{\alpha}_{2} \theta(i+1,1)+\bar{\beta}_{2} \theta(i+1,2)+\bar{\gamma}_{2} \theta(i+1,3)+----------=\bar{\phi}_{2} \\
& \text { - - - - - } \\
& \bar{\alpha}_{n} \theta(i+1, n-1)+\bar{\beta}_{n} \theta(i+1, n)+\bar{\gamma}_{n} \theta(i+1, n+1)+--------=\bar{\phi}_{n} \\
& \left(\bar{\alpha}_{n+1}+\bar{\gamma}_{n+1}\right) \theta(i+1, n)+\bar{\beta}_{n+1} \theta(i+1, n+1)=\bar{\phi}_{n+1}
\end{aligned}
$$

where

$$
\begin{array}{ll}
\bar{\alpha}_{k}= & \frac{1}{\operatorname{Pr}(\Delta Y)^{2}}+\frac{V(i, j)}{2 \Delta Y}, \quad \bar{\beta}_{k}=-\left[\frac{2}{\operatorname{Pr}(\Delta Y)^{2}}+\frac{U(i, j)}{\Delta X}\right], \\
\bar{\phi}_{k} & =-\frac{U(i, j) \theta(i, j)}{\Delta X}-E k\left(\frac{U(i+1, j+1)-U(i+1, j-1)}{2 \Delta Y}\right)^{2} \\
\text { for } \mathrm{k}=1,2 \ldots \mathrm{n}+1 & \bar{\gamma}_{k}=\frac{1}{\operatorname{Pr}(\Delta Y)^{2}}-\frac{V(i, j)}{2 \Delta Y},
\end{array}
$$

Equation (12) can be written as

$$
V(i+1, j)=V(i+1, j-1)-\frac{\Delta Y}{2 \Delta x}(U(i+1, j)+U(i+1, j-1)-U(i, j)-U(i, j-1)), j=1,2, \ldots . . n
$$

The numerical solution of the equations is obtained by first selecting the parameter that are involved such as $\mathrm{Gr} / \mathrm{Re}, \mathrm{M}$ and Pr. Then by means of a marching procedure the variables $\mathrm{U}, \mathrm{V}, \theta$ and $\mathrm{P}$ for each row beginning at row $(i+1)=2$ are obtained using the values at the previous row ' $i$ '. Thus, by applying equations (7), (8) and (9) to the points $1,2, \ldots, n$ on row $i, 2 n+2$ algebraic equations with the $2 n+2$ unknowns $U(i+1,1), U(i+1,2)$, $\mathrm{U}(\mathrm{i}+1, \mathrm{n}), \mathrm{P}(\mathrm{i}+1), \theta(\mathrm{i}+1,1), \theta(\mathrm{i}+1,2), \ldots \theta(\mathrm{i}+1, \mathrm{n}), \theta(\mathrm{i}+1, \mathrm{n}+1)$ are obtained. This system of equations is then solved by Gauss - Jordan elimination method. Equations (10) are then used to calculate V(i+1,1), $\mathrm{V}(\mathrm{i}+1,2), \ldots, \mathrm{V}(\mathrm{i}+1, \mathrm{n})$. 


\section{Results And Discussion}

The numerical solution of the equation is obtained first selecting the parameters that are involved such as $\mathrm{Gr} / \mathrm{Re}$, Ek and $\operatorname{Pr}$. For fixed $\operatorname{Pr}=0.7$ and different values of $\mathrm{Gr} / \mathrm{Re}$ and $\mathrm{Ek}$, the velocity profiles are shown in figures 3 to 5, the temperature profiles are shown in figures 6 to 8 and pressure profiles are shown in figures 9 to 11 .

Figures 3 to 5 show the velocity profiles for fixed $\mathrm{X}$ as can be seen, vary closed to the channel inlet, the heating effects are not yet felt and further downstream, the heating causes the fluid accelerate near the hot wall and decelerate near the unheated wall (adiabatic wall) resulting in distortion of velocity profiles to satisfy the continuity principle. With further increase in heating rates, this distortion becomes more severe and results into flow reversal near the adiabatic wall. However the velocity profile recovers and attains it asymptotic fully developed parabolic profile. A skewness in the velocity profiles also appear as the fluid moves towards the hot wall $(\mathrm{Y}=1)$. The velocity profiles are not effect for increasing Eckert number Ek and for fixed Prandtl number $\mathrm{Pr}$ and buoyancy parameter $\mathrm{Gr} / \mathrm{Re}$.

Figures 6 to 8 shows the development of temperature profile for fixed buoyancy parameter $\mathrm{Gr} / \mathrm{Re}$ and Eckert number Ek. These figures show how the temperature profiles are developing approaching there invariant analytical fully developed profiles. For the asymmetric heating conditions the temperature profiles will developed from the entrance till approach it's a linear profiles of the fully developed region where the fluid flows in laminated layers and all the heat transferred from the heated wall goes to the cold wall through the fluid laminated layers. It is seen that the temperature profiles are effect for increasing Eckert number Ek and for fixed $\mathrm{Gr} / \mathrm{Re}$ and Prandtl number Pr at $\mathrm{r}_{\mathrm{T}}$ for different fixed $\mathrm{X}$ values.

The development of pressure profiles are shown in figures 9 to 11 for buoyancy aided flow. These figures shows how the two hydrodynamic parameters are developing downstream of the channel at different heating rates represented buoyancy parameter $\mathrm{Gr} / \mathrm{Re}$. These negative values of the pressure will continue increasing due to the negative pressure gradient for the cases of pure forced convection $(\mathrm{Gr} / \mathrm{Re}=0)$. The pressure profiles are not effect for increasing Eckert number Ek and for fixed Prandtl number Pr and buoyancy parameter Gr/Re.
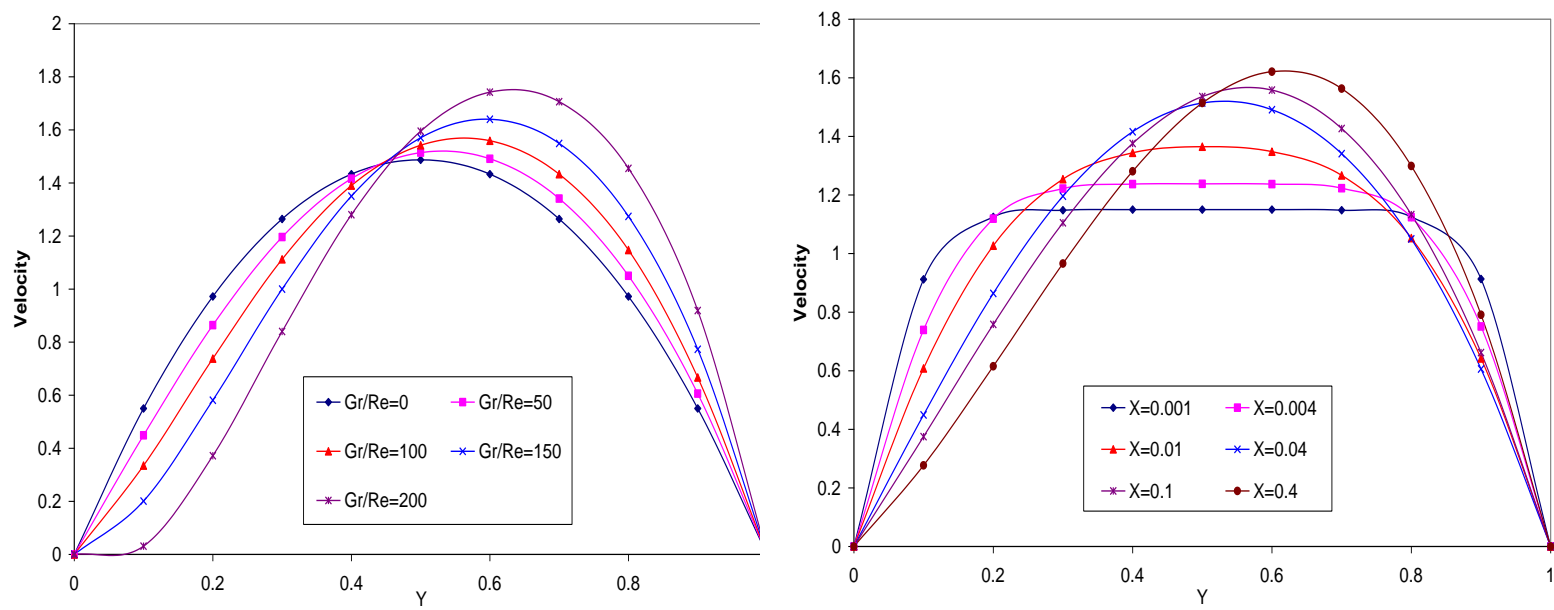

Figure 3: Velocity profile for fixed $\mathrm{X}=0.04$

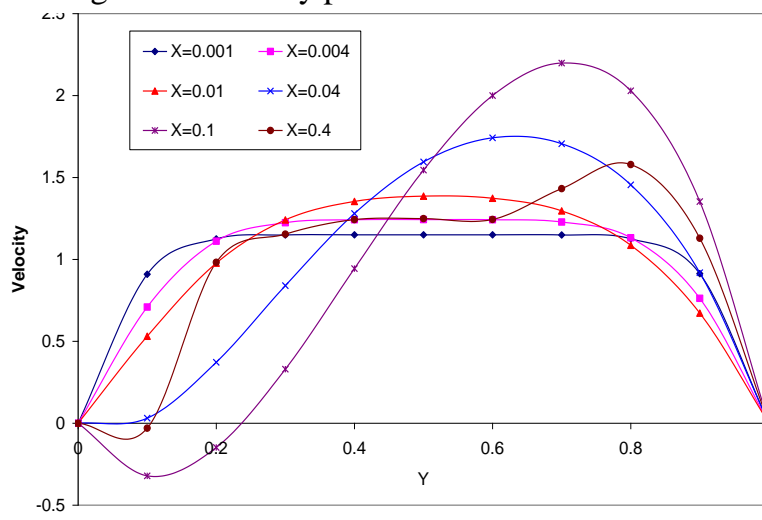

Figure 4: Velocity profile for fixed $\mathrm{Gr} / \mathrm{Re}=50$

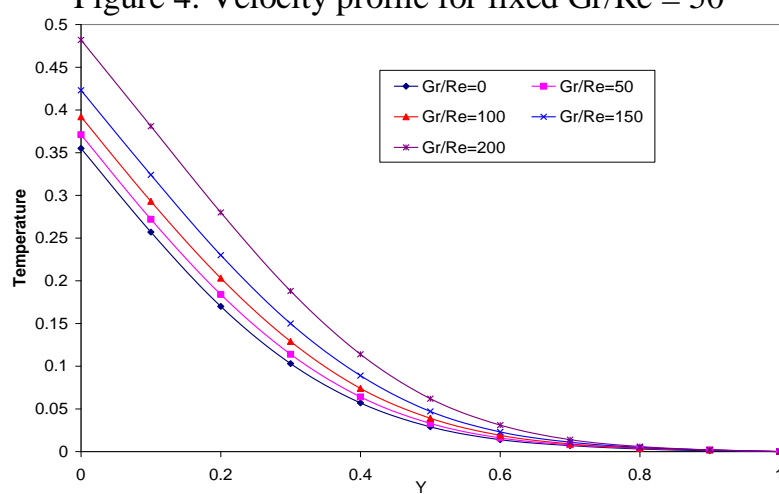

Figure 5: Velocity profile for fixed $\mathrm{Gr} / \mathrm{Re}=200$

Figure 6(a): Temperature profile for fixed $\mathrm{X}=0.04$ and $\mathrm{Ek}=0$ 


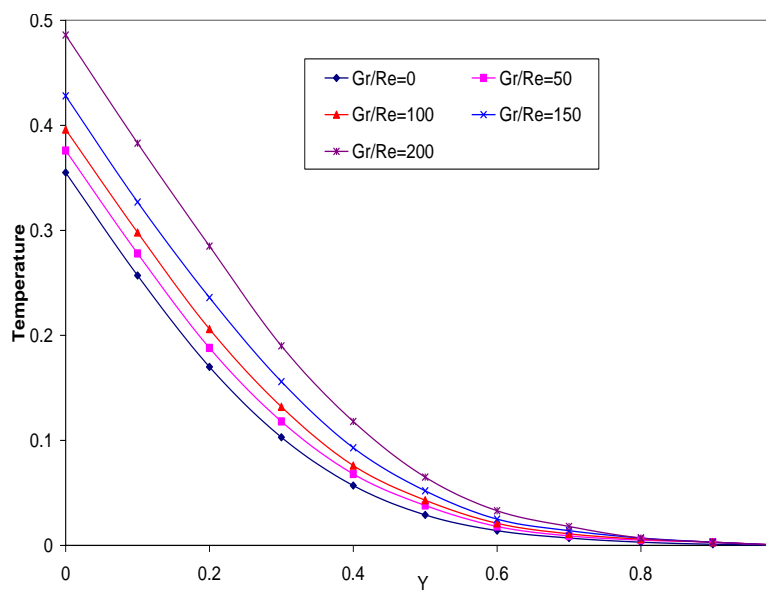

Figure 6(b): Temperature profile for fixed $X=0.04$ and $\mathrm{Ek}=1$

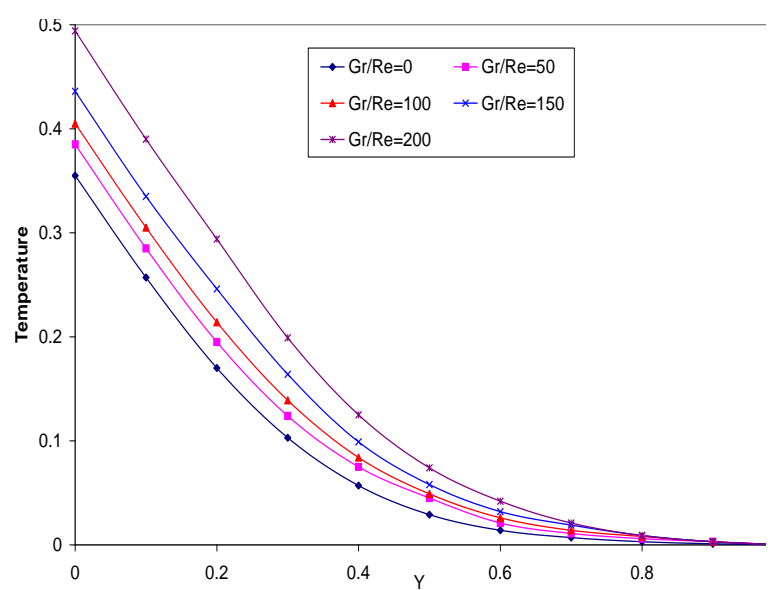

Figure 6(d): Temperature profile for fixed $X=0.04$ and $\mathrm{Ek}=10$

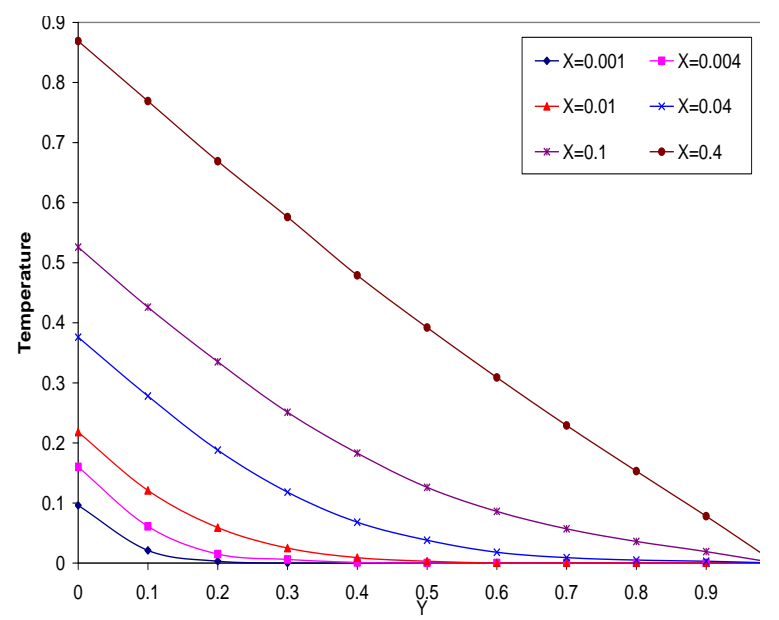

Figure 7(b): Temperature profile for fixed $\mathrm{Gr} / \mathrm{Re}=50$ and $\mathrm{Ek}=1$

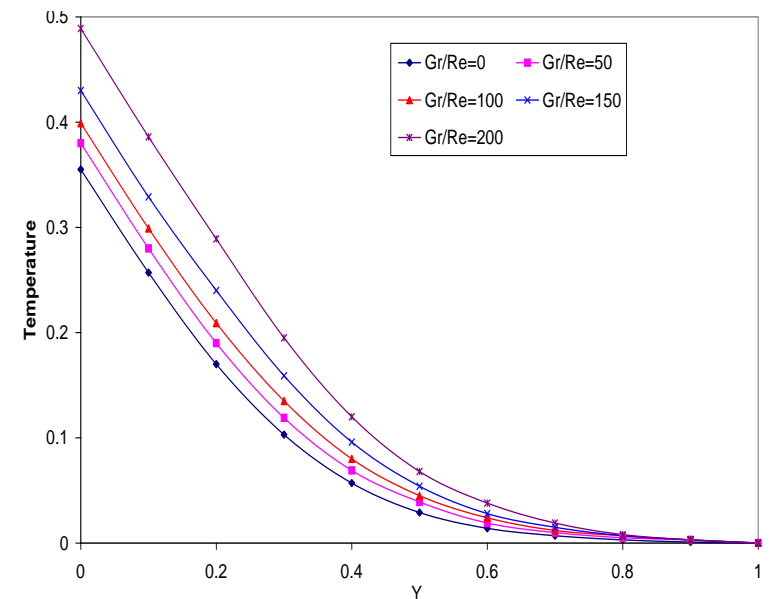

Figure 6(c): Temperature profile for fixed $X=0.04$ and $\mathrm{Ek}=5$

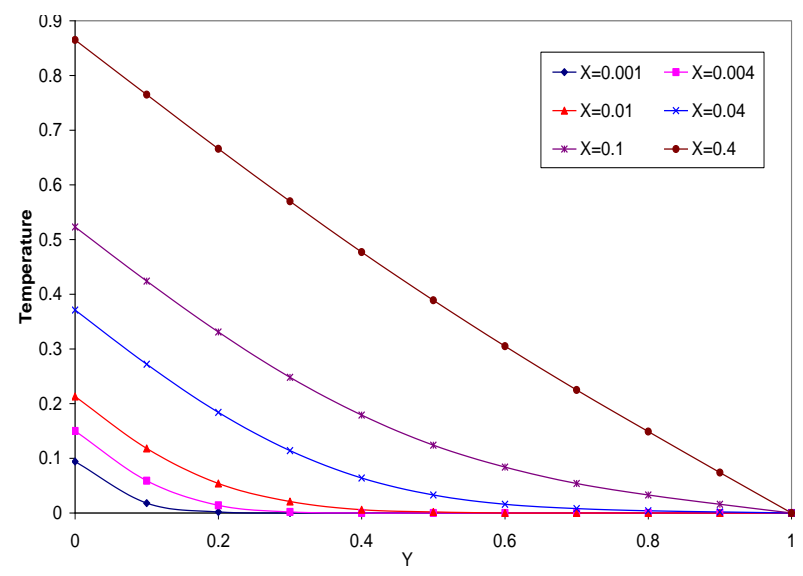

Figure 7(a): Temperature profile for fixed $\mathrm{Gr} / \mathrm{Re}=50$ and $\mathrm{Ek}=0$

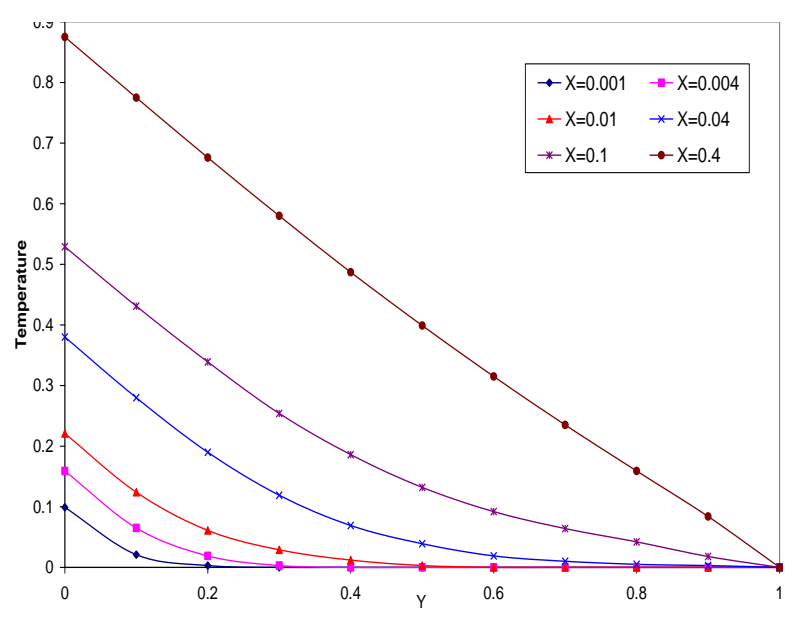

Figure 7(c): Temperature profile for fixed $\mathrm{Gr} / \mathrm{Re}=50$ and $\mathrm{Ek}=5$ 


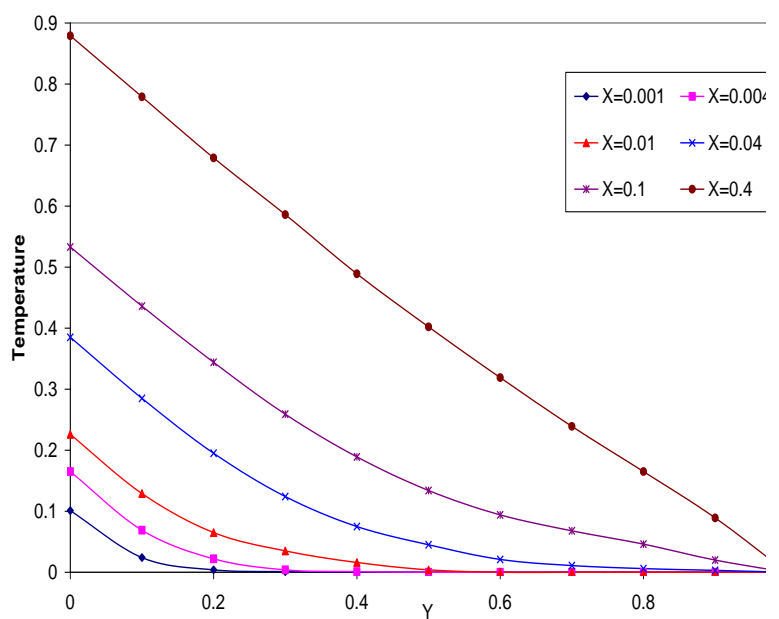

Figure 7(d): Temperature profile for fixed $\mathrm{Gr} / \mathrm{Re}=50$ and $\mathrm{Ek}=10$

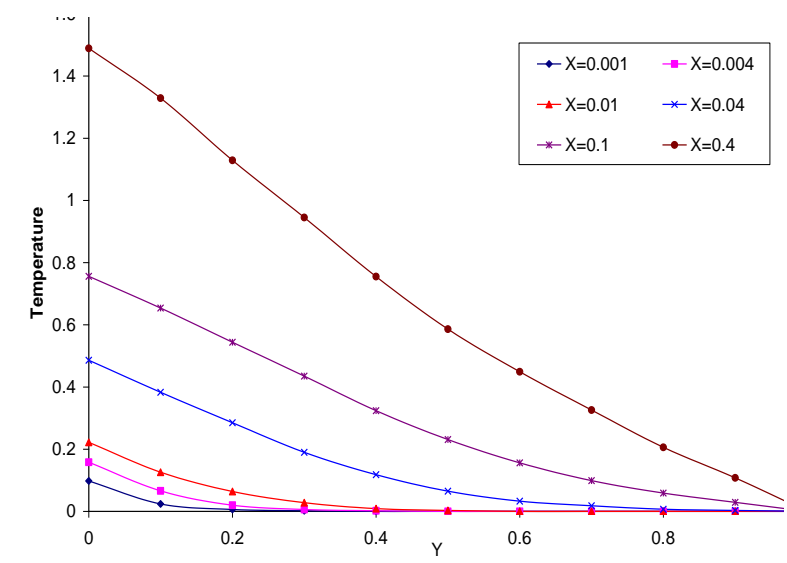

Figure 8(b): Temperature profile for fixed $\mathrm{Gr} / \mathrm{Re}$ $=200$ and $\mathrm{Ek}=1$

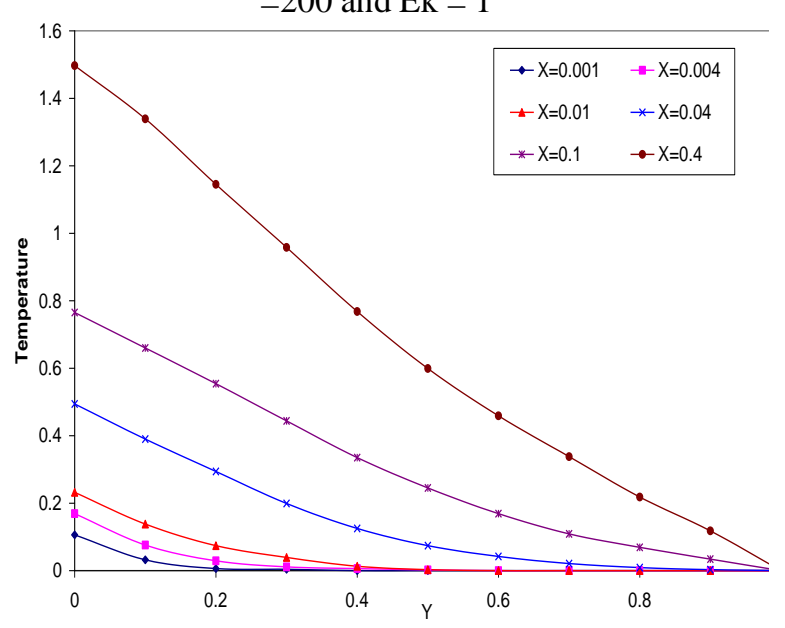

Figure 8(d): Temperature profile for fixed $\mathrm{Gr} / \mathrm{Re}$ $=200$ and $\mathrm{Ek}=10$

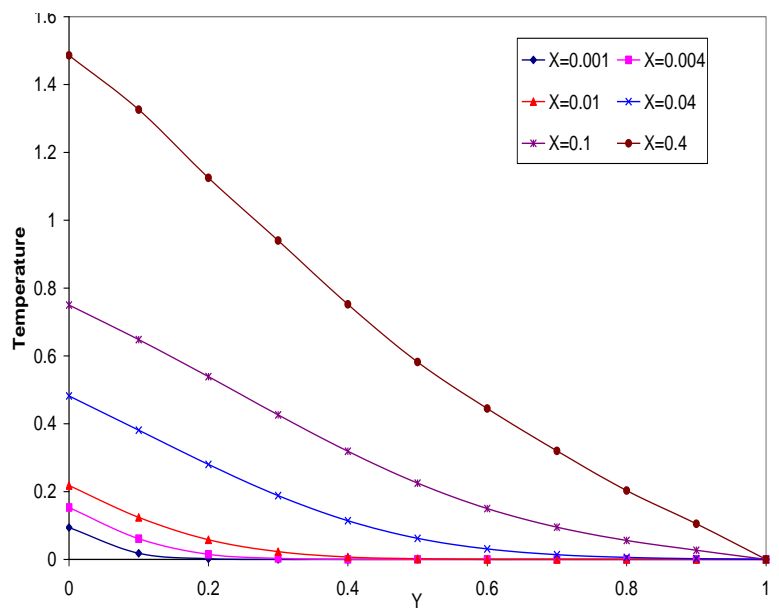

Figure 8(a): Temperature profile for fixed $\mathrm{Gr} / \mathrm{Re}=200$ and $\mathrm{Ek}=0$

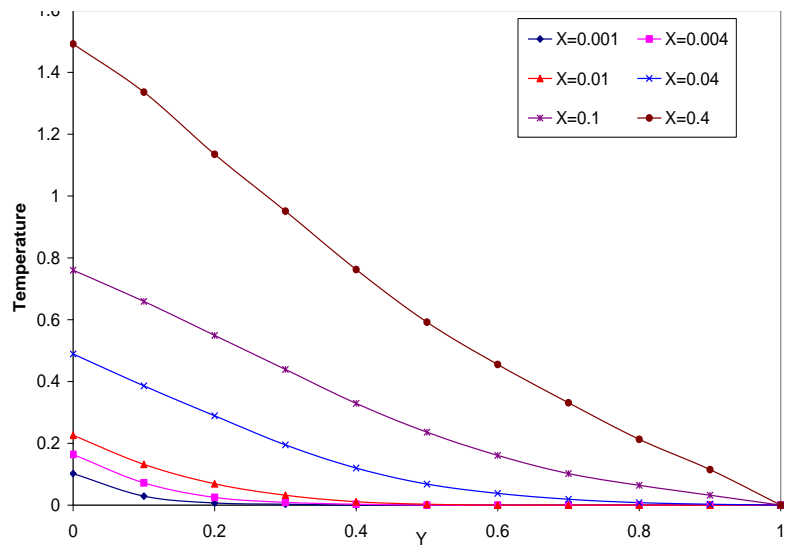

Figure 8(c): Temperature profile for fixed $\mathrm{Gr} / \mathrm{Re}=200$ and $\mathrm{Ek}=5$

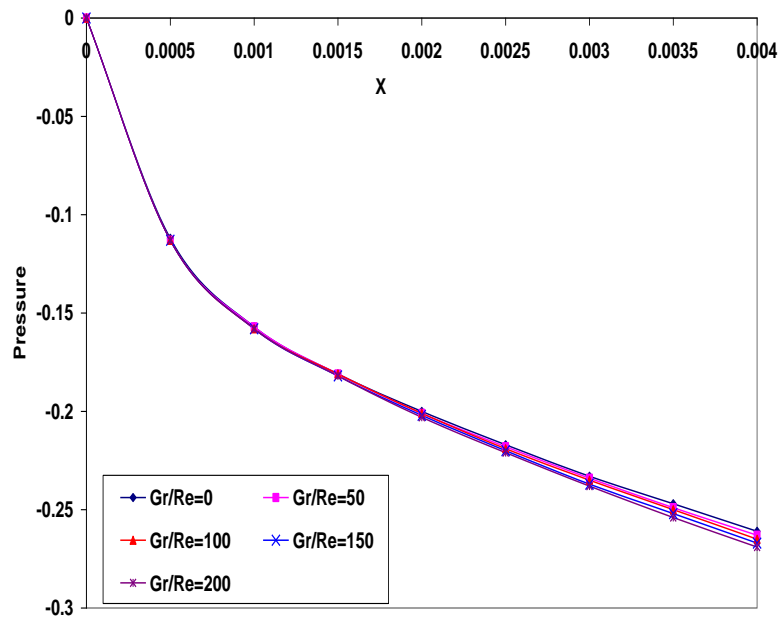

Figure 9: Pressure profile 


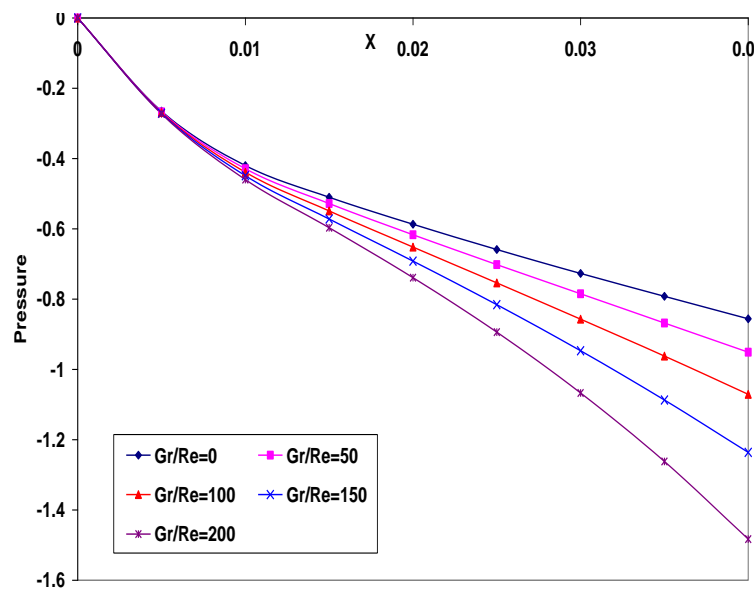

Figure 10: Pressure profile

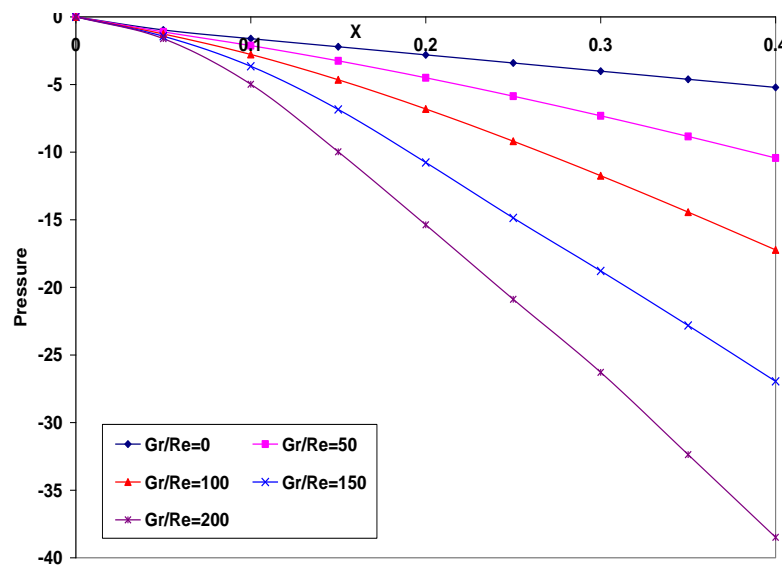

Figure 11: Pressure profile

\section{References}

[1] Aung. W. Handbook of Single-Phase Convective Heat Transfer, Wiley, New York, 1987.

[2] Aung. W., and Worku, G., ASME. J. Heat Transfer, Vol. 108, pp.299- 304, 1986.

[3] Aung. W., and Worku, G., ASME. J. Heat Transfer, Vol. 108, pp.485- 488, 1986

[4] Barletta, A., Int. J. Heat Mass Transfer, Vol.45, pp.641-654, 200

[5] Barletta, A., Int. J. Heat Mass Transfer Vol.48, pp 2042-2049, 2005.

[6] Barletta, A. Zanchini, E., Int. Commun. Heat Mass Transfer Vol. 28, pp.1043-1052, 2001.

[7] Barletta, A., and Zanchini, E., Int. J. Heat Mass Transfer Vol.44, pp 4267-4275, 2001

[8] Bodoia, J.R., and Osterle, J.F., ASME. J. Heat Transfer, Vol. 84, pp.40-44, 196

[9] Chamkha Ali, J., Int. J. Heat Mass Transfer, Vol.45, pp.2509-2525, 200

[10] Chen, Y.C., and Chung, J.N., ASME J. Heat Transfer, Vol.120, pp.127-131, 1998

[11] Chen, Y.C., and Chung, J.N., J. Fluid Mech., Vol.325, pp.29-51, 1996

[12] Evans, G., and Greif, R., Int. J. Heat Mass Transfer, Vol.40, No.10, pp.2419-2430, 1997.

[13] Gau C., Yih, K.A., and Aung, W., ASME J. Heat Transfer, Vol.114, pp.928-938, 199

[14] Reddy B.R.B., Int. J. Comp. and Applied Mathematics, Vol.7, No.1, pp.91-101, 2012

[15] Yih Nen Jeng and Jiann Lin Chen., Int. J. Heat and Fluid Flow, Vol.16, pp.25-35, 1995. 